\title{
ПРОТОКОЛЫ ЗАСЕДАНИЙ ОБЩЕСТВА АНЕСТЕЗИОЛОГОВ И РЕАНИМАТОЛОГОВ САНКТ-ПЕТЕРБУРГА
}

Президент общества - А.В.Щеголев, ученый секретарь - Р.Е.Лахин, ресрерент - Д. М. Широков

598-е заседание 25.01.2017 г.

Председатель - В.А.Глущенко

\section{ЛЕКЦИЯ}

В.А.Глущенко (НИИ онкологии им. Н.Н.Петрова, Санкт-Петербург). Повышение безопасности проведения эпидуральной анестезии.

Эпидуральная анестезия (ЭА) является методом, позволяющим ограничить действие хирургического стресса, обеспечивая защиту пациентов при минимальном воздействии на гомеостаз. Однако осложнения ЭА не позволяют считать метод абсолютно безопасным. Наиболее частыми осложнениями ЭА являются артериальная гипотензия и брадикардия. Основной фактор риска развития сердечно сосудистых осложнений - превышение сенсорного блока выше уровня сегмента $\mathrm{Th}_{5}$. Наиболее эффективные методы профилактики - инфузионная терапия в сочетании с симпатомиметиками и использование методик, ограничивающих широту симпатической блокады.

Технические осложнения связаны с нарушением методики пункции и катетеризации эпидурального пространства (ЭП). Незаращение по средней линии желтой связки встречается с частотой до $30 \%$, поэтому основным фактором риска повреждения листка твердой мозговой оболочки является несоблюдение методики потери сопротивления (методика Долиоти).

Разработанные математические формулы для различных вариантов пункции ЭП позволили создать номограммы величин зон безопасности [Кобрина В.В., 2009, 2015]. Рассматриваются детали метода, вопросы технических сложностей пункции и катетеризации ЭП, даны практические рекомендации, разбираются механизмы узлообразования эпидурального катетера. Знание и учет величины зоны безопасности позволяет объективно оценить вероятность осложнений пункции и снизить их риск.

\section{ДОКЛАД}

В.А.Глущенко, С.А.Розенгард (НИИ онкологии им. Н.Н.Петрова, Санкт-Петербург). Программа ускоренного восстановления после хирургических вмешательств. Взгляд анестезиолога.

В основе «Программы ускоренного выздоровления» (ПУВ) лежит принцип мультидисциплинарного подхода, где важная роль отводится анестезиологу-реаниматологу на всех этапах лечения пациента. В докладе рассматриваются положения ПУВ, за которые отвечает анестезиолог-реаниматолог, с позиции доказательной медицины. Подготовка к операции должна начинаться еще на догоспитальном этапе: информирование о ПУВ и специализированная подготовка у пациентов высокого риска. До операции оценивают алиментарный статус и при наличии недостаточности производят его коррекцию. Рекомендуется использование специализированных углеводных смесей и отказ от полного голодания, отмена седативных препаратов перед операцией. Важная роль отводится предупреждению тромбоэмболических осложнений, а также антимикробной профилактике.

Для анестезии используются управляемые летучие (севофлуран, десфлуран) и внутривенные (пропофол) анестетики, опиоиды (фентанил) и антидеполяризующие миорелаксанты малой и средней продолжительности действия. При лапаротомии целесообразно использовать эпидуральную анестезию или другие методики регионарной анестезии. Важная роль отводится мультимодальному подходу к анестезии и аналгезии. Инфузия растворов - по принципу индивидуально ориентированной терапии, объем которой основывается на данных малоинвазивных методов контроля гемодинамики. В послеоперационном периоде, по возможности,- отказ от инфузионной терапии с переходом на пероральный прием жидкости. Отказ от рутинного использования назогастральной интубации; стремление к скорейшему удалению мочевого катетера. Поддержание нормотермии с помощью специальных систем обогрева, согревающих матрасов и использования теплых растворов. Использование мультимодального подхода снижает риск возникновения послеоперационных тошноты и рвоты и способствует ранней активизации пациента. В послеоперационном периоде - ранняя мобилизация, которая осуществляется в условиях адекватной аналгезии.

Реализация принципов ПУВ возможна на основе мультидисциплинарного подхода команды единомышленников при наличии необходимого оборудования и лекарственного обеспечения.

Ответы на вопросы. Для реализации ПУВ в наших отделениях реанимации в условиях дефицита персонала и отсутствия младших сестер по уходу за больными нужны реабилитологи. При проведении рестриктивной инфузионной терапии нужно ориентироваться на показатели центральной и периферической гемодинамики, если применяется инвазивный мониторинг. В других случаях информативна оценка состояния периферических тканей, темпа диуреза, уровня ЦВД, состояния слизистых оболочек.

\section{ДЕМОНСТРАЦИИ}

1. Ф.А.Кононец, С.А.Розенгард (НИИ онкологии им. Н.Н.Петрова, Санкт-Петербург). Седация детей 
с опухолями головного мозга, осложненными синдромом Иценко - Кушинга, при проведении лучевой терапии.

Атипичная тератоидно-рабноидная опухоль (АТРО) головного мозга (ГМ) составляет $10-20 \%$ от опухолей ЦНС детей младше 3 лет, у $50 \%$ из них она осложняется синдромом Иценко - Кушинга.

Одним из основных методов в комплексном лечении АТРО является лучевая терапия (ЛТ), для проведения которой необходим 3-5-минутный период полной неподвижности. Этого удаётся добиться использованием специальной закрывающей все лицо термопластичной маски, а у детей младшего возраста - еще и глубокого медикаментозного сна. Обеспечение седации при этой процедуре у данной категории пациентов вызывает определенные сложности: невозможность поддержания проходимости дыхательных путей (ДП) с помощью надглоточных девайсов, почти $100 \%$ частота возникновения обструкции верхних ДП у детей с синдромом Иценко - Кушинга при использовании терапевтических доз пропофола, невозможность присутствия анестезиолога рядом с ребенком во время лечения. В зарубежной литературе опубликовано довольно большое число исследований безопасного и эффективного использования дексмедетомидина (дексдора) интраназально для седатации детей при проведении различных лечебных и диагностических процедур.

Пациент Т., 2 года 6 мес. Диагноз АТРО ГМ. Масса тела 26 кг (возрастная норма 13 кг). Введение пропофола в дозе 4-5 мг/кг болюсно и 4-6 мг / (кг •ч) для поддержания сопровождалось нарушением дыхания и критическим снижением сатурации, что требовало обеспечения проходимости верхних ДП и вспомогательной вентиляции легких. Учитывая приведенные выше сложности этих манипуляций, от использования данной методики пришлось отказаться. Использовали методику седатации на основе интраназального применения дексдора в дозе 2 мкг/кг массы тела за 1 ч до процедуры. Непосредственно перед началом лечения вводили пропофол в дозе 1-2 мг/кг болюсно и 0,5-1 мг/(кг •ч) для поддержания. Этого было достаточно, чтобы добиться необходимого уровня седации. Нарушений дыхания, гемодинамики и снижения сатурации не было.

По этой методике проведено 11 процедур. Как правило, пациенты просыпались через 10-15 мин после введения пропофола, полное пробуждение наступало через 90-150 мин от момента начала лечения. При осмотре ЛОР-врачом слизистой оболочки носа пациентов патологических изменений не зарегистрировано. Таким образом, интраназальное использование дексдора в дозе 2 мкг/кг позволяет значительно снизить дозу пропофола и избежать эпизодов нарушения дыхания у детей.

\section{Прения}

В.А.Глущенко. Хочется услышать мнение коллег из педиатрического университета, поскольку мы столкнулись с тем, что применение классической схемы с пропофолом практически невозможно. Применение ларингеальной маски чрезвычайно сложно, а проведение анестезии с интубацией трахеи на 10-15 мин нецелесообразно. Вынужденно использовали дексдор, хотя его применение у детей не разрешено юридически. Мы привлекали локальный этический комитет для решения вопроса во благо ребенка.

Ю.С. Александрович. Эта работа вызывает восхищение. Как проблема обездвиживания при серьезной процедуре у таких детей решается в мире и у нас в стране? За рубежом $80 \%$ препаратов, которые применяются у детей, используется off-label. 323-й федеральный закон об охране здоровья граждан дает нам возможность выполнить эту процедуру по решению консилиума в составе 3 человек (лечащий врач, заведующий отделением, главный врач), что полностью может обезопасить врача от всяких проблем. Это очень важная демонстрация. Нужно расширять применение препарата в клинике.

А.Н.Грицай. В 2014 г. в Сиднее на Всемирном конгрессе анестезиологов американский анестезиолог докладывал о летальном исходе у ребенка после применения пропофола. В дальнейшем они отказались от пропофола и вернулись к схеме применения кетамина с дормикумом, в том числе в виде назального спрея и сиропа. Эта схема более безопасна в плане развития апноэ у детей. Если можно в одном растворе смешивать кетамин с дексдором, то почему бы не использовать эту смесь, в которой кетамин нивелирует эффект брадикардии, вызываемый дексдором у детей? Это безопасно даже при опухолях головного мозга, поскольку в малых дозах кетамин не повышает ВЧД.

2. С.А.Розенгард, Я.О.Веденин, Е.В.Наперов, А.А.Николаев (НИИ онкологии им. Н.Н.Петрова, СанктПетербург). Случай успешного лечения диализзависимой дисфункции почек при синдроме лизиса опухоли у ребенка с острым лейкозом.

Частота развития этого синдрома при остром лейкозе составляет от 5 до $23 \%$. Выраженное бластное пропитывание органов и тканей требует экстренной химиотерапии. Это сопряжено с опасностью массивного эндотоксикоза, обусловленного поступлением в кровь продуктов распада опухолевых клеток с развитием гиперкалиемии, гиперфосфатемии, гиперурикемии и острого повреждения почек. Потребность в диализе при этом составляет около $12 \%$.

Пациент Б., 8 лет, находился на лечении в отделении детской онкологии с 27.10.2016 г. Диагноз: острый лимфобластный лейкоз с поражением переднего средостения, почек, синдром острого лизиса опухоли. Гемодиализ с 27.10. по 28.10.2016 г.

При поступлении состояние средней тяжести. В анализах крови: л. 46×10\%/л, бласты $55 \%$; креатинин - 246 мкмоль/л, ЛДГ 4027 Ед/л, миелограмма: бласты более $90 \%$. По данным КТ: резкое увеличение средостения и почек. Клинически: олигурия (500 мл/сут). Срочно в профильном отделении начата химиотерапия. Эндолюмбально введено: метотрексата 12 мг, цитозара 50 мг, преднизолона 10 мг после гипергидратации и инфузии $4 \%$ раствора гидрокарбоната натрия. Через 5 ч - резкое ухудшение общего состояния: рвота, анурия, спутанность сознания. При поступлении в отделение реанимации: состояние крайне тяжелое, кома II. АД 50/30 мм рт. ст.; ЧСС 120 уд/мин. По данным ЭКГ - резкие нарушения проводимости миокарда левого желудочка. Дыхание поверхностное, 34 в 1 мин. Сатурация крови $82 \%$. В анализе артериальной крови: лактат 4 ммоль/л, $\mathrm{pH} 7,1$, калий 10 ммоль/л. Экстренно выполнена интубация трахеи, начата ИВЛ, инотропная поддержка норадреналином. После катетеризации правой бедренной вены начат сеанс высокопоточного продленного гемодиализа: скорость кровотока 80 мл/мин, скорость диализата 2000 мл/ч, скорость ультрафильтрации - 50 мл/ч. Продолжительность процедуры 11 ч. Через 2 ч - улучшение общего состояния, содержание калия 6,0 ммоль/л, стабилизация гемодинамики. 
К концу процедуры содержание калия 4,0 ммоль/л, полиурия. Экстубация трахеи на фоне полного восстановления функции внешнего дыхания и сознания. На 2-е сутки переведен в профильное отделение для продолжения противоопухолевого лечения. В дальнейшем состояние удовлетворительное.

\section{Прения}

В.А.Глущенко. В нашем городе нет клиник эфферентной терапии (ЭТ) для детей. У нас есть аппаратура для ЭТ, сертифицированные специалисты и опыт работы со взрослыми, но опыта работы с детьми у нас не было. Выяснилось, что выездная бригада проводить ЭТ детям также не может. Перевод ребенка в другую клинику из-за тяжести состояния был невозможен, но ребенок весил около 30 кг, и аппаратура для взрослых ему подошла. Процедура ЭТ дала очень хороший результат. Очень важный вопрос для Комитета по здравоохранению, потому что с такой проблемой может столкнуться не только наше отделение.

3. А.А.Хряпа, Ю.С.Полушин, И.В.Шльк (ПСПбГМУ им. акад. И.П.Павлова). Роль анестезиолога в обосновании хирургической тактики лечения пациентки с раком желудка, осложненным кровотечением и критическим митральным рестенозом.

Пациентка В., 69 лет, поступила в нашу клинику для планового оперативного вмешательства по поводу рака желудка, осложненного субкомпенсированным стенозом выходного отдела с рецидивирующим кровотечением из опухоли. При осмотре анестезиологом было констатировано наличие сердечной недостаточности III-IV степени по NYHA. По результатам трансторакальной ЭхоКГ диагностирован критический митральный стеноз с трикуспидальной недостаточностью и легочной гипертензией, требующий хирургической коррекции с применением искусственного кровообращения (ИК). Несмотря на наличие показаний для экстренной операции на желудке, высокий риск осложненного течения вследствие патологических изменений сердца поставлен вопрос о последовательности и сроках выполнения вмешательств. Решение принимали совместно хирурги-онкологи, кардиохирурги с приоритетным учетом данных анестезиолога-реаниматолога о риске анестезии и возможных осложнениях в послеоперационном периоде. Выполнена симультанная поэтапная операция (сначала дистальная резекция желудка, затем протезирование митрального клапана и пластика трехстворчатого клапана). Общая продолжительность вмешательства 645 мин (абдоминальный этап - 160 мин, кардиохирургический -425 мин). Продолжительность ИК - 138 мин, время пережатия аорты - 96 мин. При анестезии использованы ограничительная тактика инфузионной терапии, протективная вентиляция легких и ряд других целенаправленных приемов. Хотя послеоперационный период протекал тяжело, исход в конечном итоге благоприятный. Длительность пребывания в ОРИТ 8 сут, в стационаре - 30 сут.

Цель демонстрации - на конкретном примере показать необходимость мультидисциплинарного подхода при хирургическом лечении пациентов с тяжелыми сопутствующими заболеваниями и роль анестезиолога в оценке риска операции и анестезии, обосновании выбора тактики симультанных оперативных вмешательств.

\section{Прения}

А.И.Левшанков. По первому докладу. Проблема реабилитации на сегодняшний день не решена, особенно для тех больных, у которых имеется полиорганная недостаточность и которые длительно находятся на ИВЛ. Термин «ускоренная реабилитация» не очень правильный для такой категории больных. Более правильно - «непрерывная и ранняя реабилитация» с первых дней после операции, потому что наши больные умирают от гиподинамии. Это проблема, ибо у нас дефицит кадров - это первое. Во-вторых, у нас плохое техническое обеспечение - мы все делаем руками. В наших отделениях должны быть врач лечебной физкультуры, массажисты, штатный психолог.

Ю.С.Александрович. По первому докладу. Нынешняя концепция Минздрава - это персонифицированная превентивно-предиктивная медицина, которая полностью противоречит концепции «ускоренной реабилитации». Что такое быстрое восстановление? Конвейер Генри Форда! Зачем? Чтобы выполнить федеральные квоты, чтобы больше получить денег. Что может сделать анестезиолог, чтобы больной быстрее выбыл из клиники? Важнейшие аспекты: 1-й - нутритивная поддержка. 2-й - об инфузии. Варианты стратегии: рестриктивная, либеральная. Какие плюсы рестриктивной стратегии? Вода задерживается в первую очередь в легких. При рестриктивной инфузии не страдает индекс оксигенации, не требуется вентиляции. Если была операция на кишечнике, то нет отека кишки. Нет потребности в парентеральном питании.

В.А.Глущенко (председатель). В заключение благодарит докладчиков за их интересные демонстрации, профессоров А.И.Левшанкова и Ю.С.Александровича за их комментарии.

Поступил в редакцию 28.04.2017 г.

\section{9-е заседание 01.03.2017 г.}

Председатель - А.В.Щеголев

\section{ЛЕКЦИЯ}

А.А.Андреенко (ВМедА им. С.М.Кирова, СанктПетербург). Принципы решения проблемы «трудных дыхательных путей».

Лекция посвящена основным аспектам обеспечения проходимости верхних дыхательных путей во время анестезии. Представлены международные и российские данные о частоте встречаемости ситуаций «трудных дыхательных путей» (ТДП). Показано, что именно критические нарушения газообмена во время ситуаций с ТДП остаются одной из основных причин смерти во время анестезии и в послеоперационном периоде. Автор привел современную классификацию ТДП, в которой выделяют ситуации трудной вентиляции через различные устройства, а также возможный трудный инвазивный доступ к дыхательным путям. В разделе, посвященном прогнозированию ТДП в плановых и экстренных ситуациях, сформулирован дифференцированный подход на основании выявленных факторов риска. Приведены наиболее эффективные прогностические модели оценки риска ТДП.

Автор охарактеризовал основные классы устройств, применяемых в настоящее время для обеспечения вентиля- 
ции легких и выполнения интубации трахеи (надгортанные устройства, видеоларингоскопы, гибкие интубационные эндоскопы, оптические стилеты, наборы для инвазивного доступа). Для каждого типа устройств приведены основные функциональные возможности, методики применения, потенциальные проблемы и осложнения при их использовании, указаны клинические ситуации, в которых наиболее эффективно их применение.

В лекции представлен современный алгоритм решения проблемы «непрогнозируемых» ТДП во время анестезии. Особый акцент сделан на обеспечении безопасности пациентов за счет ограничения числа травматичных неэффективных манипуляций, своевременного изменения методики, обеспечении на протяжении всего времени адекватной оксигенации и как можно более ранней констатации необходимости выполнения инвазивного доступа к дыхательным путям с выбором наиболее простой методики его выполнения. Отдельно представлены особенности действий при ТДП во время экстренной анестезии. Подчеркнута необходимость прогнозирования осложнений после экстубации и обеспечения дифференцированного подхода к выполнению этой процедуры.

\section{ДОКЛАДЫ}

1. Е.Ю.Струков (ВМедА им. С.М.Кирова, СанктПетербург). Анализ результатов медицинского аудита анестезиологов-реаниматологов по вопросам практики нутриционной поддержки.

В настоящее время доказано негативное влияние недостаточности питания на летальность, частоту инфекционных осложнений, длительность пребывания в стационаре и стоимость лечения пациентов в отделениях реанимации и интенсивной терапии. Проблема нутриционной поддержки в повседневной работе врача анестезиолога-реаниматолога является многогранной и включает в себя оценку трофологического статуса, выявление пациентов с дефицитом массы тела или его угрозой, выбор метода питания и субстратного обеспечения, а также профилактику возможных осложнений при проведении самой нутриционной поддержки.

В работе представлены результаты медицинского аудита анестезиологов-реаниматологов лечебных учреждений Министерства здравоохранения и Министерства обороны РФ по теоретическим и практическим аспектам проведения нутриционной поддержки. Результаты исследования показали, что на данный момент у врачей анестезиологов-реаниматологов нет единого подхода к оценке трофологического статуса пациента. Специалисты используют различные методики (антропометрию, лабораторные исследования, использование комплексных шкал, расчет прогноза развития гипотрофии и др.), ни одна из которых не является универсальной. Далеко не все врачи оценивают потребности пациентов в белке и энергии (только у $80 \%$ и $72 \%$ соответственно), при этом зачастую используется субъективный эмпирический метод оценки. Теоретические знания врачей в области энергетического и белкового обеспечения пациентов являются удовлетворительными и соответствуют требованиям современных рекомендаций. Однако на практике почти половина врачей (45\%) не знают, какое энерго-пластическое обеспечение нужно назначать пациентам.

Можно сделать вывод о том, что обеспечение отделений реанимации и интенсивной терапии средствами для нутриционной поддержки является недостаточным. Имеются проблемы как с субстратным, так и техническим обеспечением. Около $60 \%$ врачей не имеют возможности использовать насосы-дозаторы для адекватного проведения энтерального питания, у $61 \%$ больных используются жесткие поливинилхлоридные зонды, не пригодные для долгого применения, а обеспечение стационаров смесями для парентерального и энтерального питания оценивают как «неудовлетворительное» $30 \%$ опрошенных врачей.

Данное исследование показало, что многим практикующим врачам не всегда хватает теоретических знаний в вопросах проведения нутриционной поддержки, что может крайне негативно влиять на исходы в лечении пациентов. Тем не менее, при должном организационном подходе к проблеме, повышении теоретических знаний и практических навыков медицинского персонала в области нутриционной поддержки можно значительно улучшить качество применения этого важного метода интенсивной терапии и снизить количество осложнений при его проведении.

Ответы на вопросы. Подобные опросы и исследования проводятся для того, чтобы принимать те или иные управленческие решения. Здесь можно ставить вопросы к образовательным учреждениям, профессорскопреподавательскому составу и к врачам-специалистам. У тех и других должна быть определённая мотивация, а у врачей-специалистов - к обучению, и она существует. С другой стороны, мы должны признать, что в процессе образования, даже при подготовке наших студентов, этим вопросам уделяем мало внимания. Нашим курсантам, врачам-специалистам, терапевтам вопросы питания ни на одном цикле не преподают, а дают только клиническим ординаторам в рамках дисциплины «Анестезиология и реаниматология». Все это является основанием создания циклов обучения для всех желающих повысить свой уровень знаний в области клинического питания.

Пациентов, которые нуждаются в нутриционной поддержке, обычно консультирует анестезиолог-реаниматолог. Если врачи-специалисты увидят, что пациент нуждается в нутриционной поддержке и вовремя обратятся к более компетентным специалистам, то это уже будет хорошо.

2. В.С.Афончиков, А.Н.Грицай (СПбНИИ скорой помощи им. И.И.Джанелидзе, ВМедА им. С.М.Кирова, Санкт-Петербург). Роль и место тромбоэластографии в диагностике нарушений гемостаза при критических состояниях.

Мониторинг состояния системы гемокоагуляции в настоящее время является обязательным компонентом интенсивной терапии критических состояний. Это связано с высокой частотой развития коагулопатий именно у пациентов реаниматологического профиля. Характерными особенностями приобретенных коагулопатий является их разнонаправленный характер (довольно часто встречаются как гипер-, так и гипокоагуляционные состояния) с дефицитом многих факторов системы гемокоагуляции. При большинстве критических состояний имеет место воздействие на систему гемостаза факторов, как способствующих развитию гиперкоагуляции, так и приводящих к развитию гипокоагуляции. Коагулограмма, которая в большинстве лечебно-профилактических учреждений представлена определением МНО, АПТВ и подсчетом количества тромбоцитов, не дает достаточной информации для комплексной оценки состояния всех звеньев системы гемокоагуляции. Также «рутинная» коагулограмма не отражает функционального состояния тромбоцитарного звена 
и никак не оценивает завершающую (посткоагуляционную) стадию свертывания крови. При исследовании содержания фибриногена в плазме определяют содержание данного белка, но не представляется возможным оценить качественные параметры образующегося полимера фибрина, которые могут значительно изменяться, в частности, под влиянием коллоидных плазмозаменителей.

Для решения данной проблемы в СПбНИИ СП им. И.И.Джанелидзе в течение 5 лет используется методика модифицированной тромбоэластографии (ТЭГ). Она может быть информативной, если параллельно оценивать тромбоэластограммы проб цельной крови и обедненной тромбоцитами плазмы. Анализ данных, полученных в ходе исследования проб крови 30 здоровых доноров резерва, позволил нам определить нормальные значения разницы показателей тромбоэластограммы цельной крови и обедненной тромбоцитами плазмы. Превышение нормальных значений разницы показателей $\mathrm{R}, \mathrm{K}, \mathrm{MA}, \mathrm{G}$ и Angle $\alpha$ - свидетельствует о повышении активности тромбоцитарного звена или недостаточной активности гуморального звена системы гемокоагуляции, превышение нормальных значений разницы показателей LY30 - об усиленной ретракции кровяного сгустка. Последний показатель крайне актуален, так как при анализе классической тромбоэластограммы любое повышение показателя LY30 трактуется как гиперфибринолиз и служит обоснованием для применения ингибиторов фибринолиза. Наша клиническая практика показала, что у большинства пострадавших с тяжелой сочетанной травмой признаки гиперфибринолиза отсутствуют, но имеет место повышение ретракции сгустка, которая обусловлена значительным снижением гематокритного числа и гиперактивностью тромбоцитарного звена системы гемокоагуляции.

Таким образом, применение методики ТЭГ (в модифицированном нами варианте) позволяет получить ценную информацию о состоянии основных звеньев системы гемокоагуляции у пациентов, находящихся в критическом состоянии, и перейти от эмпирической заместительной терапии к целенаправленной коррекции приобретенных коагулопатий.

Ответы на вопросы. Я настоятельно рекомендую использовать ТЭГ при больших по объему плановых оперативных вмешательствах, при которых либо есть данные о наличии коагулопатии в анамнезе, либо больные принимали антикоагулянты или антиагреганты. С помощью ТЭГ мы оцениваем звенья гемостаза, даем им критериальноколичественную оценку и принимаем решение: отложить операцию или подготовить к операции определённые трансфузиологические средства, подкрепляя решение не только умозрительно, а вполне объективными данными. У тяжелых пострадавших ранняя травматическая коагулопатия, травматический шок, тяжелый сепсис и септическая коагулопатия требуют контроля для назначения антиагрегантов и оптимального подбора доз. Или, например, необходимо решить вопрос - нужно ли пациенту срочно переливать тромбоцитный концентрат? Тромбоцитов у него $15 \cdot 10^{9} /$ л, а какова их функция? Ведь бывают случаи, когда их мало, но они активные, молодые, крупные. Тромбоэластограмма показывает, что такого качества тромбоцитов может быть вполне достаточно. Не нужно сразу вводить тромбоцитный концентрат, а необходимо разобраться в причинах тромбоцитопении. Если она аутоиммунная, то назначить глюкокортикоиды. Бывают ситуации, когда можно отказаться от ненужной гемотрансфузии на основании того, что нет кровотечения и данных тромбоэластограммы достаточно, чтобы исправить такое критическое положение. Методика ТЭГ позволяет документировать коагулопатию и таким образом обосновать назначение прокоагулянтов, особенно если есть данные о гиперфибринолизе и имеется угроза кровотечения при оперативном вмешательстве. К вопросу о порядке и частоте использования метода ТЭГ при анестезии или в интенсивной терапии я подошел бы с осторожностью. Есть стационары, где тромбоэластографа нет, не было и в ближайшее время не будет. Абсолютные показания к ТЭГ - это синдром ДВС, ранняя травматическая коагулопатия. Травма с массивной кровопотерей и синдромом ДВС - это ситуации, в которых в европейских странах настоятельно рекомендуют проводить ТЭГ и на основании её оценивать гемостаз и гиперфибринолиз. Но говорить об обязательном применении ТЭГ сегодня, на мой взгляд, преждевременно.

\section{ДЕМОНСТРАЦИИ}

1. С.Г.Парванян, Д.А.Шелухин, М.О.Соловьева (Всероссийский центр экстренной и радиационной медицины им. А.М.Никифорова). 300 кг для анестезиолога не вес.

Пациент С., 36 лет, страдающий морбидным ожирением (масса тела 296 кг при росте 210 см, ИМТ 67,1) обратился в наш центр для проведения бариатрической операции лапароскопическим доступом. После длительного подготовительного периода, взвешенной оценки рисков и выработки комплекса мер по предотвращению осложнений была выполнена операция дистального желудочного шунтирования лапароскопическим доступом. Метод анестезии - общая анестезия с интубацией трахеи и ИВЛ. В предоперационном периоде, а также во время анестезии и операции, в раннем послеоперационном периоде были преодолены многочисленные технические трудности, связанные с антропометрическими параметрами пациента и особенностями его положения на операционном столе. Использовали схему анестезии, обеспечивающую максимально быстрое восстановление пациента в раннем послеоперационном периоде с последующей ранней мобилизацией. Она включала фиброоптическую интубацию трахеи при сохраненном самостоятельном дыхании, отказ от использования в ходе анестезии длительно действующих препаратов, использование реверсии нейромышечной блокады и антагонистов препаратов для анестезии. Результатом была ранняя активизация пациента с возможностью его вертикализации в первые часы после операции, раннее начало послеоперационной реабилитации, профилактика осложнений, связанных с вынужденной гиподинамией. Приведенная технология позволила эффективно, безопасно и комфортно провести анестезию и оперативное вмешательство пациенту с крайне высоким риском периоперационных осложнений.

Ответы на вопросы. Большая величина минутной вентиляции (около 10 л/мин) обусловлена тем, что масса пациента составила 300 кг, и при потоке кислорода 550 мл/мин концентрация кислорода в контуре начинала снижаться, поэтому минутный поток кислорода и был 600 мл/мин. Установить поток ниже не было возможности. Величина $\mathrm{pCO}_{2}$ связана с массой тела, но $\mathrm{pCO}_{2}$ в артериальной крови мы не измеряли. Для оценки необходимо прямое измерение потребления кислорода. Мы используем рекрутирование по методике Garsia - это ступенчатое нарастание ПДКВ и затем снижение по уровню комплайнса, во время лапароскопической операции это рекомендуют делать, как минимум, трижды: 
после индукции, наложения карбоксиперитонеума и после устранения давления в брюшной полости. Мы применили эту методику после индукции и в конце операции. По нашему мнению, этот маневр необходимо выполнять при лапароскопических операциях в $100 \%$ случаев.

\section{Прения}

К.М.Лебединский. Мне кажется, А.И.Левшанков прав в том, что метаболически жир менее активен, чем мышечная ткань. Наверное, если пациент весит 300 кг, нельзя считать, что у него потребление кислорода равно $3 \mathrm{X}$, где $\mathrm{x}-$ энергопотребление здорового человека с нормальной массой тела.

2. Д.А.Аверьянов, Р.С.Лакотко (ВМедА им. С.М.Кирова, Санкт-Петербург). Дифференциальная диагностика причин развития критического состояния после нейрохирургического вмешательства в положении сидя.

Больному 63 лет произведено нейрохирургическое вмешательство по поводу новообразования головного мозга супратенториальной локализации. В положении на операционном столе сидя произведена костно-пластическая трепанация черепа. На этапе выполнения доступа было отмечено краевое повреждение верхнего сагиттального синуса. Интраоперационно регистрировали снижение давления $\mathrm{CO}_{2}$ в альвеолах ниже 25 мм рт. ст. и десатурацию $-\mathrm{SpO}_{2}$ до $75 \%$. После окончания оперативного вмешательства и перевода пациента в отделение реанимации отмечено нарастание явлений дыхательной и сердечно-сосудистой недостаточности. Был проведен комплекс лечебно-диагностических мероприятий для дифференциальной диагностики и интенсивной терапии развившегося синдрома полиорганной недостаточности. Чреспищеводная эхокардиография позволила провести дифференциальную диагностику причин развития критического состояния. У больного развился синдром острого повреждения легких, который привел к неблагоприятному исходу.

Ответы на вопросы. Из объективных методов оценки воздушной венозной эмболии «золотым» стандартом является череспищеводная электрокардиография, которая ввиду остроты ситуации выполнена интраоперационно не была. Однако косвенно по степени снижения напряжения углекислого газа на выдохе можно установить, что воздушная эмболия была массивной. Несмотря на то, что дефект был устранен немедленно, такие эпизоды повторились около 4 раз. Пациент умер от острого повреждения легких, которое явилось осложнением массивной воздушной эмболии.

\section{Прения}

Д.А.Шелухин. В отношении определения объема эмболии. В ее оценке может помочь ангиопульмонография, по которой можно оценить объем перфузии малого круга кровообращения. Хотя проводились измерения, из доклада не ясно, какими были сердечный выброс и минутный объем кровообращения, был ли компонент сердечной недостаточности. На мой взгляд, причиной летального исхода была тяжелая гипоксия, потому что индекс оксигенации составил 52, a $\mathrm{pH}-7,18$ - это тяжелейшая гипоксия! Но не были во время предприняты адекватные меры для устранения гипоксии. Что можно было сделать? Одна из методик, которая применяется при ТЭЛА, - это экстренное подключение экстракорпоральной мембранной оксигенации.

А.В.Щеголев (председатель). Благодарит всех выступающих. Говоря о докладе Е.Ю.Струкова, еще раз подчеркнул важность этой аналитической работы. А.А.Андриенко координирует вопросы по трудным дыхательным путям, мы проводим мастер-классы. От коллег, которые приходят и обучаются методикам интубации трахеи в трудных условиях слышим вопрос: «А почему у нас ничего этого нет?» Ответ: «А у вас никогда ничего не появится, если мы не будем иметь аналитической информации». Именно поэтому я буду рекомендовать в рамках Федерации, в рамках всей страны, проводить вот такие скрининговые исследования по уровню знаний, по технической оснащенности, о возможных путях развития. К сожалению, у нас довольно мало организаторов здравоохранения, которые понимают, например, что кормить правильно и хорошо - это дешевле для больницы, чем экономить на средствах и тратить деньги на антибиотики и лечение гнойно-септических осложнений. Второй момент, который является чрезвычайно важным. Городская комиссия по изучению летальных исходов запросила у меня дополнительные персоналии экспертов, потому что число жалоб и историй болезни на разбор увеличивается в геометрической прогрессии. Давайте спросим друг друга: «До этого заседания каждый ли из нас знал, что существуют национальные рекомендации по питанию?» Думаю, что нет, работа в качестве лечащего врача предусматривает, например, знание о том, что написано в законах, стандартах и клинических рекомендациях, потому что их невыполнение может привести к серьезным осложнениям. Не так давно в одной из городских больниц скончалась молодая девушка, у которой был гемолитико-уремический синдром. Я удивился тому объему обследований, которому пациентка была подвергнута в городской больнице, были полностью выполнены клинические рекомендации. Эксперт Росздравнадзора выяснил, что дежурный врач-реаниматолог назначил пациентке реополиглюкин, по этому факту возбуждено уголовное дело, потому что данный препарат был назначен не по показаниям. В связи с этим необходимо понимать, что мы делаем и когда мы делаем. Если вы читаете социальные сети, то видите, к чему подводится система здравоохранения. Теперь о ней высказываются практически все. Все считают её положение катастрофическим и ухудшающимся, но ответственность за это несут врачи, и поэтому наши знания и наша образованность очень важны.

Комментируя доклад моих коллег из Центра МЧС, я восхищен. У каждого в практике, наверное, есть такие случаи. Р.С.Лакотко только сейчас начал выполнять работу по диагностике воздушной эмболии. Из своего уже более чем 20-летнего опыта могу сказать, что, как правило, частота этих осложнений начинает меняться тогда, когда меняется бригада ассистентов, потому что это проблема исключительно хирургическая. К сожалению, поздравить нас не с чем - этот пациент скончался, несмотря на выполнение всех необходимых мероприятий. Давайте учиться вместе.

Поступил в редакцию 28.04.2017 г.

\section{0-е заседание 29.03.2017 г.}

Председатель - Ю.С.Полушин

\section{ЛЕКЦИЯ}

И.В.Шльк (ПСПбГМУ им. акад. И.П.Павлова). Целенаправленная интенсивная терапия септического шока. 
В лекции приводятся современные определения, классификация и критерии диагностики сепсиса и септического шока. Рассматриваются основные направления интенсивной терапии, основанные на международных рекомендациях и результатах последних исследований, в частности, либеральный и рестриктивный подходы при проведении инфузионной терапии септического шока, обоснование выбора препаратов вазопрессорной и инотропной поддержки. Обсуждается необходимый объем мониторинга и критерии эффективности интенсивной терапии с позиции оценки информативности таких показателей, как ЦВД, содержание лактата, сатурации центральной венозной крови и артериовенозная разница по $\mathrm{CO}_{2}$ при лечении септического шока. Представлены новые концепции рекомендаций Surviving Sepsis Campaign-2016 и «Сепсис-3», рассматривающие этот патологический процесс как угрожающую жизни органную дисфункцию, вызванную разбалансированной реакции макроорганизма на инфекцию. Показано, что изменение представлений о сепсисе и септическом шоке, а также анализ результатов их лечения приводят к пересмотру подходов к интенсивной терапии, что имеет и клинико-экономический эффект.

\section{ДОКЛАдЫ}

1. А.А.Афанасьев, Ю.С.Полушин, И.В.Шльк, Д.А.Малинина (ПСПбГМУ им. акад. И.П.Павлова). Роль биомаркёров в дифференциальной диагностике причин развития ССВР и СПОД у пациентов в критических состояниях.

Целью сообщения является демонстрация эффективности применения прокальцитонина и пресепсина для подтверждения или исключения инфекционной природы развития ССВР и СПОД в различных клинических ситуациях. Несмотря на то, что их применяют в клинической практике давно, ряд вопросов, связанных с оценкой специфичности в той или иной клинической ситуации, уточнения диагностически значимого диапазона, трактовкой динамики изменения содержания в плазме крови, по-прежнему обсуждаются. С клинических позиций, это определяет сложность своевременной констатации развития сепсиса у пациентов, находящихся в критическом состоянии. В определенной степени облегчить и ускорить диагностический поиск может использование различных биомаркёров инфекции на разных этапах обследования и лечения, особенно в качестве экспресс-диагностики, что и было показано в данном исследовании. Изучение содержания пресепсина и прокальцитонина проводили в группе пациентов, у которых исключался инфекционный процесс как причина развития ССВР и (или) СПОД после интраабдоминальных оперативных вмешательств. Диагноз «сепсис» ставился согласно критериям «Сепсис-3». В ходе исследования были установлены значимые различия содержания пресепсина и прокальцитонина у пациентов с сепсисом и ССВР неинфекционного генеза. При сравнении информативности прокальцитонина и пресепсина для диагностики сепсиса была выявлена более высокая спецефичность изменений пресепсина у больных с сепсисом.

\section{Прения}

Ю.С.Полушин. В клинике часто наблюдается злоупотребление использованием биомаркёров, именно это обусловливает гипердиагностику сепсиса. Данное сообщение лишний раз продемонстрировало, что надо очень взвешен- но подходить к интерпретации результатов обследования. Необходимо учитывать, что при развитии травматической болезни, как и при любом другом повреждении, имеет место цитокиновый «взрыв», и биомаркёры также в нем участвуют, поэтому в первую очередь надо учитывать клиническую картину, а уже потом изменения биомаркёров.

2. А.Е.Кобак, А.А.Хряпа (ПСПбГМУ им. акад. И.П.Павлова). Оптимизация тактики предоперационного обследования и подготовки пациентов с реконструктивными вмешательствами на магистральных артериях.

В докладе представлены результаты исследования, целью которого была оптимизация предоперационного обследования и подготовки больных, которым выполняли оперативное вмешательство на аорте и магистральных сосудах нижних конечностей. В предоперационном периоде всем пациентам выполняли холтеровское мониторирование, стресс-эхокардиографию, коронарографию. У 97,4\% пациентов, имевших 2 и более факторов риска, при коронарографии были верифицированы гемодинамически значимые поражения коронарного русла. В группе пациентов при отсутствии признаков ишемии по результатам рутинного обследования (жалобы анамнез, ЭКГ, холтеровское мониторирование, эхокардиогафия) при проведении нагрузочных тестов признаки ишемии были выявлены почти у $1 / 3$ из них, что в дальнейшем повлияло на выбор стратегии хирургического лечения. Полученные данные показали низкую значимость методики холтеровского мониторирования у пациентов с мультифокальным атеросклерозом и высокую значимость стресс-эхокардиографии. Стресс-эхокардиографию следует обязательно включать в алгоритм обследования больных с генерализованными формами атеросклероза, независимо от результатов оценки риска осложнений по Lee, a коронарографию - при риске в 2 балла и более. Выявление бессимптомной формы ИБС может изменить очередность этапов хирургического лечения (кардиохирургического и сосудистого) и тактику анестезии.

Oтветы на вопросы. Сочетание чреспищеводной стимуляции и применения $\beta$-блокаторов является безопасной методикой ведения пациентов с поражениями сердца, позволяющей обходиться без вазопрессоров и дополнительных лекарств в интраоперационном периоде. Необходимо оценивать кардиоспецифические ферменты в раннем послеоперационном периоде, чтобы исключать или подтверждать фактор повреждения миокарда. Эти пациенты не подходят для рутинного обследования, им необходим индивидуальный осмотр анестезиолога, при выявлении факторов риска скрытой ИБС им необходимо расширять спектр обследования, иногда приходится сначала выполнять коронарное вмешательство, а затем операцию на сосудах.

\section{ДЕМОНСТРАЦИИ}

1. М.Г.Ковалев, А.Л.Акопов, С.М.Черный, А.А.Русанов, А.В.Герасин, Н.В.Казаков, А.А.Ильин, И.В.Нестерова, Т.Ю.Злочевская, М.А.Васильева (ПСПбГМУ им. акад. И.П.Павлова). Вариант анестезиологического обеспечения хирургического лечения больного с постинтубационным, посттрахеостомическим стенозом шейного отдела трахеи и тяжелой коронарной патологией.

Цель демонстрации - обсудить особенности анестезиологического обеспечения при хирургическом лечении пациентов с декомпенсированным постинтубационным, 
посттрахеостомическим стенозом трахеи (ПИ-ПТС СТ). Представлен случай анестезиологического сопровождения у пациента К., 44 лет, с ПИ-ПТС СТ шейного отдела трахеи в верхней трети и тяжелым поражением венечных сосудов сердца. Особенностью наблюдения явился перенесенный 3 мес назад трансмуральный Q-переднебоковой ОИМ, осложненный острой сердечно-сосудистой и дыхательной недостаточностью, делирием, что потребовало проведения длительной ИВЛ с отсроченным стентированием передней межжелудочковой ветви левой венечной артерии непокрытым стентом. Показанием к переводу в специализированную клинику явилось развитие ПИ-ПТС СТ, требовавшего хирургического лечения. Декомпенсация стеноза на раннем этапе обследования больного потребовала эндопротезирования трахеи непокрытым металлокаркасным стентом в условиях седатации дексмедетомидином, поскольку бужирование трахеи, проведение операции и общей анестезии по экстренным показаниям представляло серьезный риск. С учетом хирургических рисков была пересмотрена антикоагулянтная терапия. Установка стента повлияла на тактику обеспечения проходимости дыхательных путей и ИВЛ без интубации трахеи с использованием ларингеальной маски и катетера для струйной ВЧ ИВЛ перед операцией циркулярной резекции трахеи при сохранении самостоятельного дыхания больного на фоне седатации дексмедетомидином. Была проведена комбинированная общая анестезия с использованием внутривенных анестетиков и ингаляцией десфлурана. Инфузия дексмедетомидина облегчила экстубацию в операционной и была прекращена через 18 ч после окончания операции. Больной был переведен на 2-е сутки из ОРИТ и выписан на 12-е сутки после операции без признаков дыхательной недостаточности. Обсуждаемый вариант анестезиологического обеспечения позволяет расширить диапазон принятия решений с применением передовых медицинских технологий и снизить риски общей анестезии и операции при лечении стенозов трахеи.

Ответы на вопросы. Необходимо оценивать давление в манжете не «на глаз», а имеющимся оборудованием, поскольку именно фактор перераздувания манжетки интубационной трубки может быть основным фактором повреждения трахеи с развитием стенозов. Необходимо адекватно седатировать пациентов с использованием максимально безопасных и эффективных препаратов, поскольку факт возбуждения и возникновение делирия являются дополнительным причинным фактором повреждения трахеи. Необходимо грамотно оценивать подход к таким пациентам, поскольку растет объем реанимационной помощи и, следовательно, частота повреждений трахеи.

2. И.В.Бовкун, Д.В.Соколов, Е.Г.Гаврилова (ПСПбГМУ им. акад. И.П.Павлова). Роль селективной ЛПС-сорбции в комплексной терапии больных с грамотрицательным сепсисом.

Цель демонстрации - на конкретном примере обсудить показания и возможности экстракорпоральной гемокоррекции при лечении пациентов с септическим шоком.

Пациент К., 64 лет, поступил в клинику для планового оперативного лечения по поводу рака пищевода.
Больному выполнена одномоментная резекция пищевода c внутригрудным пищеводно-желудочным анастомозом в условиях сочетанной анестезии с использованием фторсодержащих ингаляционных анестетиков. Однако ранний послеоперационный период осложнился развитием септического шока с быстрым прогрессированием синдрома мультиорганной дисфункции (дыхательной, почечной, кишечной, сердечно-сосудистой, церебральной). По данным бактериологических посевов материала после бронхоальвеолярного лаважа, выявлена Pseudomonas aeruginosa, а методом ЕАА экспресс-теста отмечена высокая активность эндотоксина. В совокупности с клиническими проявлениями септического шока это явилось показанием для экстракорпорального удаления эндотоксина. Селективная липополисорбция выполнена с применением картриджа с полимиксином В. Было проведено 2 процедуры с интервалом в 24 ч. Гемоперфузия с полимиксином В, наряду с сеансами гемодиализа, способствовала стабилизации состояния на фоне проводимой интенсивной терапии септического шока. После завершения курса экстракорпорального удаления липополисахарида у больного регистрировали снижение показателя активности эндотоксина и содержания прокальцитонина. В клинической картине у пациента после заключительной процедуры ЛПС-адсорбции отметили нормализацию показателей гемодинамики со снижением потребности в вазопрессорной поддержке норадреналином, увеличение индекса оксигенации, снижение содержания палочкоядерных нейтрофилов в периферической крови, снижение тяжести состояния по шкале SOFA. Больной был переведен на 18-е сутки из ОРИТ и выписан на 22-е сутки после операции в относительно удовлетворительном состоянии.

Данный клинический пример продемонстрировал позитивный опыт использования селективной ЛПС-адсорбции в комплексном лечении септического шока. Использование экспресс-теста для оценки активности эндотоксина позволяет сделать выбор метода экстракорпоральной гемокоррекции у пациентов с сепсисом более целенаправленным.

Ответы на вопросы. С учетом улучшения состояния пациента ИВЛ не была продолжительной. По нашим данным, применение ЛПС-адсорбции может повлиять на исход заболевания.

\section{Прения}

Ю.С. Полушин (председатель). Благодарит всех выступающих; у нас получилась интересная повестка. Все пациенты анестезиолого-реаниматологического профиля, как мы видели сегодня из представленных докладов и демонстраций, нуждаются в индивидуальном подходе и взвешенных решениях. Надо максимально противодействовать упрощению обследования тяжелобольных, как того требуют экономические реалии, и при необходимости даже настаивать на более углубленном обследовании. Появляются новые технологии, как мы увидели на примере липополисорбции, которые надо активно внедрять в лечебный процесс. Это значит, что нам есть к чему стремиться и есть над чем работать.

Поступил в редакцию 28.04.2017 г. 